\title{
Personal, Interpersonal, and Media Predictors of Fear of Ebola
}

\author{
James Price Dillarda $\left[\right.$ and Chun Yang ${ }^{b}$
}

aDepartment of Communication Arts and Sciences, Pennsylvania State University, University Park, Pennsylvania, USA; bManship School of Mass Communications, Louisiana State University, Baton Rouge, Louisiana, USA

\begin{abstract}
Fear of infectious disease has the potential to damage local economies, disrupt health care delivery systems, and diminish immune functioning, whether or not the risk is objectively high. The appearance of Ebola in the United States offered an opportunity to study the causes of fear in a real-world event. Shortly after the death of the first Ebola patient diagnosed in the United States, survey data were gathered $(N=849)$ from residents of Dallas and U.S. citizens outside of Texas. Fear was positively associated with age (younger), gender (female), and ethnicity (non-White), but not geographic proximity (Dallas vs. not Dallas). Exposure to Ebola-related information via interpersonal channels (friends/family, acquaintances/coworkers) corresponded with higher levels of fear, but the findings for media channels were more varied, showing positive effects (newspapers/ magazines), negative effects (Internet), and null effects (TV/radio). The study provides insight into the personal, interpersonal, and media correlates of fear of Ebola.
\end{abstract}

KEYWORDS: Fear; media; interpersonal; communication; infectious disease; Ebola

Although infectious diseases can produce devastating biological effects, nonbiologic outcomes may be equally consequential (Lempel, Epstein, \& Hammond, 2009). Fear can decrease immune functioning, produce delays in care seeking, and damage the local economy (Van Bortel et al., 2016). Furthermore, such effects may occur whether or not fear of the disease is objectively justified (Smith, 2006).

These observations underscore the importance of understanding fear as a potential health problem in its own right. Surprisingly, only a handful of studies have considered fear as the focus of investigation (e.g., Nelissen, Beullens, Lemal, \& van den Bulck, 2015). The 2014 arrival

CONTACT James Dillard, PhD • E-mail: jpd16@psu.edu • Department of Communication Arts and Sciences, Pennsylvania State University, University Park, PA 16802, USA 
of Ebola in the United States presented an opportunity to address this understudied issue by examining fear in response to a public health crisis, notably, one that experts believed posed almost no danger to the public at large.

The project embraced three broad questions. The first, concerned with audience segmentation, focused on person-level correlates of fear. Given the possibility of affective disparities, we tested for associations between fear and gender, age, ethnicity, and proximity to the threat. Second, in light of the intense news coverage of Ebola, we considered the relationship between media exposure and fear. To complete the picture (third), we examined the role of interpersonal communication. This was justified on the grounds that individuals often share information about their emotional states and the causes thereof (Rimé, 2007). Our overarching goal was to produce a layered analysis of the correlates of fear.

\section{A Brief History of Ebola in the United States}

Ebola produces a range of symptoms that include internal and external hemorrhaging (World Health Organization, 2015) and an average case fatality rate of $50 \%$. The outbreak that began in Africa in March 2014 eventually developed into the largest epidemic of Ebola in history (Centers for Disease Control and Prevention, 2015). By summer of that year, the epidemic began to draw increased attention from the U.S. press and government that continued to grow in subsequent months. In a September 16 press release, Lamar Alexander, senior Republican on the Senate's health committee, said, "This is one of the most explosive, dangerous, deadly epidemics in modern times.... There is no known cure. Half of those who get sick die" (U.S. Senate Committee on Health, Education, Labor, and Pensions, 2014).

On September 30, 2014, Eric Thomas Duncan, a resident of Dallas who had been traveling in Liberia, tested positive for Ebola. He died 8 days later. Duncan's two nurses, Nina Pham and Amber Vinson, contracted the disease and became the second and third cases of Ebola in the United States. What followed has been described as a media frenzy (Bruinius, 2014). Indeed, media sources frequently used the phrase 


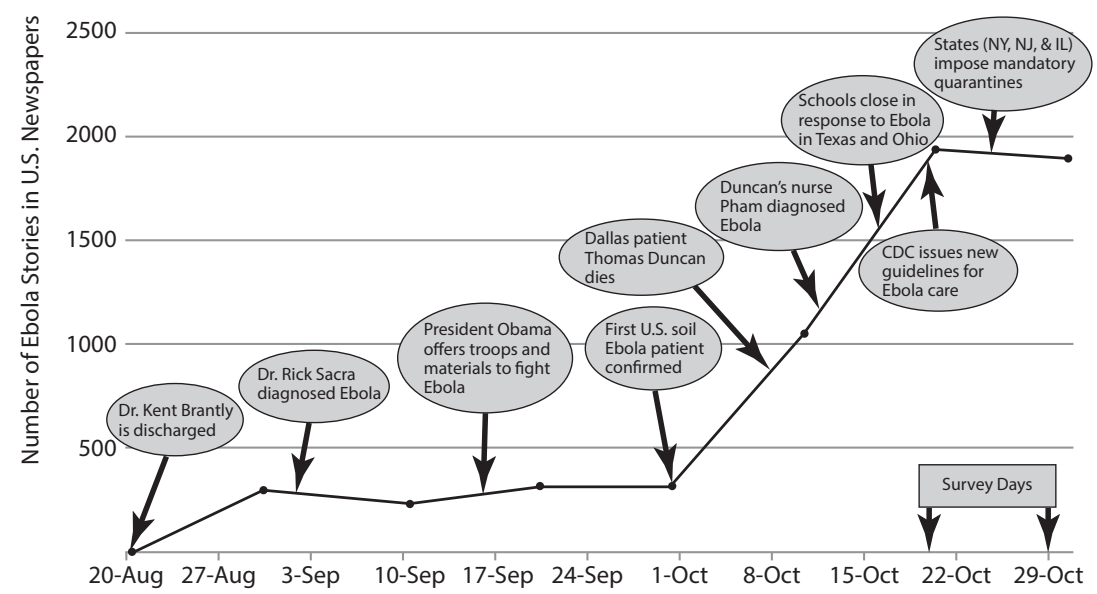

FIGURE 1 Timeline of Ebola events and media coverage. In the LexisNexis Academic News Sources database, we searched for articles with "Ebola" as keyword in both the title and the body in U.S. newspapers from August 20 to October 29, 2014. To assess trends in media coverage, we gathered data about the total number of Ebola-related news stories for 10-day periods. The results are plotted as data points and connected with lines.

"epidemic of fear" to describe the mood of the country (e.g., Gilsinan, 2014). A Washington Post story reported that "this is both a biological plague and a psychological one, and fear can spread even faster than the virus" (Sun, Dennis, Bernstein, \& Achenbach, 2014). Collectively, these events warrant characterization of the situation as a megacrisis (Sellnow-Richmond, George, \& Sellnow, 2018). Figure 1 illustrates media coverage of the disease along with notable Ebola-related events.

\section{The Nature and Effects of Fear}

Fear is a negatively valenced emotion that follows from the perception that one is at risk of harm (Frijda, 1986; Lazarus, 1991). It is indexed in the English language by a family of terms that range from worried to terrified. Synonyms that lie near the center of the intensity continuum include scared, afraid, and frightened (Ortony, Clore, \& Collins, 1988). ${ }^{1}$ At moderate levels, fear provides the motivational basis for self-protective behaviors, such as information seeking (Kim \& Niederdeppe, 2013). But, when fear becomes more intense, it can constrict the perceptual 
field and preclude longer range thinking. Some writers have asserted that infectious diseases may have special power to instill fright because viral agents are invisible, colorless, and odorless (Alcabes, 2009). The inability to directly perceive the threat can escalate worry into intense fear and dread (Alcabes, 2009).

Problems associated with fear of infectious disease play out at three levels (Van Bortel et al., 2016). Among individuals, fear may interfere with the ability to perform one's job and to successfully enact social relationships (Tamir, 2016), as well as decrease job satisfaction and increase stress (Hartley, Davila, Marquart, \& Mullings, 2013). Fear and related disorders, such as posttraumatic stress syndrome, have also been associated with diminished cardiovascular fitness (Suls \& Bunde, 2005), decreased immune system functioning (Segerstrom, Solomon, Kemeny, \& Fahey, 1998), and degraded psychological health (Silver et al., 2013). At the community level, fear can accelerate the spread of disease (Schulz et al., 2016), cause delays in care seeking (Yamanis, Nolan, \& Shepler, 2016), disrupt health care delivery systems (Barrett \& Brown, 2008), and diminish trust in health services (Van Bortel et al., 2016). Fear can also produce unwanted outcomes at the state and national levels. For instance, areas impacted by infectious diseases may experience loss of investment and decreased tourism/travel (Lempel et al., 2009). In sum, fear has the potential to produce seriously undesirable outcomes depending on its intensity.

\section{Personal Predictors of Fear: Demographics}

It is generally accepted that there is value in understanding responses to disasters via demographic grouping (Liu, Fraustino, \& Jin, 2017). Certain demographic variables have been associated with perceived risk and emotional response. One is gender. Men perceive lower levels of risk relative to women, a finding that is typically attributed to sociopolitical factors rather than biology or knowledge deficits (Finucane, Slovic, Mertz, Flynn, \& Satterfield, 2000; Flynn, Slovic, \& Mertz, 1994). Similarly, recent work has found that men report lower levels of fear to a variety of stimuli. This relationship holds even after controlling for gender role adherence (Campbell et al., 2016). 
Age, another demographic descriptor, generally shows an inverse correlation with intensity of negative affect (Charles, Reynolds, \& Gatz, 2001). Socioemotional selectivity theory explains this relationship in terms of greater motivation to down-regulate negative feelings (Carstensen, 2006). In contrast, the strength and vulnerability integration model emphasizes ability. Presumably, older individuals are more skilled at emotion regulation than their younger counterparts (Charles, 2010).

There is also evidence that ethnicity corresponds with perceived risk and emotional response. Whites generally perceive lower levels of environmental risk compared to non-Whites (Finucane et al., 2000; Flynn et al., 1994), and following disasters, Whites show lower levels of sadness, which is typically correlated with fear, than non-Whites (Chu, Seery, Ence, Holman, \& Silver, 2006). It has been argued that the tendency for persons of African descent (vs. Whites) to report higher levels of affect can be explained in terms of cultural differences that place a higher value on emotions and emotional expression (White \& Parham, 1990).

The goal of this study was not to evaluate competing explanations for these findings. Rather, we aimed to assess whether the same demographic variables might be useful for identifying segments of the population that are especially prone to fear of infectious disease. Purely on the basis of prior findings, the following was expected:

H1: Fear is negatively associated with (a) gender (male), (b) age, and

(c) ethnicity (White).

\section{Personal Predictors of Fear: Proximity}

Appraisal theories of emotion posit an explicit causal sequence that leads to emotion arousal (Frijda, 1986; Lazarus, 1991). First, some change takes place in the environment. Next, the individual appraises the implications of the change for his or her well-being. Assuming that the change is seen as relevant, some emotion results, the type and intensity of which depend on other appraisals. Fear, for example, requires that the individual see the change as involving impending danger. 
Reason suggests that geographic proximity to a threat should enhance fear, probably due to perceptions of increased susceptibility and, perhaps, severity. Research has borne this out. Ruiz and Hernandez (2014) found that residents of the Canary Islands who were closer to a volcanic eruption reported higher fear than those who were more distant. Other studies have shown that fear increases as a function of physical proximity to acts of terrorism (Holman, Garfin, \& Silver, 2014; Stitka, Bauman, \& Mullen, 2004). Furthermore, analysis of Twitter data revealed that the percentage of tweets expressing fear in countries with confirmed cases of Ebola was higher than in adjacent countries, which was higher than in distant countries (Zhuang, Peng, \& Tang, 2018). Given the appearance of Ebola in Dallas and the failure of the health care system there to contain the disease, we anticipated that residents of Dallas would experience higher levels of fear than persons in other parts of the United States:

H2: Fear is positively associated with physical proximity to the threat.

\section{Media and Interpersonal Predictors of Fear}

It is possible for individuals to encounter hazards, such as infectious disease, by contracting the malady themselves or by directly observing its effects in others. This was true for the health professionals in Texas who cared for Eric Thomas Duncan, Nina Pham, and Amber Vinson. However, we suspect that it is more common for people to learn about health threats from other people (including media) than directly. This was the case for the millions of Americans who did not have direct contact with Duncan, Pham, or Vinson. Thus it seems quite likely that risk appraisal and the fear that follows from it are shaped by a variety of indirect social processes. The social amplification of risk model holds that individuals, groups, and institutions can act as amplification stations that serve to amplify or attenuate risk perception when they communicate about the hazard (Kasperson, Kasperson, Pidgeon, \& Slovic, 2003). ${ }^{2}$ Two such stations are media and interpersonal networks. An abundance of research has shown that frequency of exposure to risk information via mediated or interpersonal channels is a positive 
predictor of fear and/or risk. For instance, a meta-analysis of cultivation research reported that frequency of exposure to television is positively associated with perception of real-world violence (Morgan \& Shanahan, 1997). Other work has indicated a positive relationship between media exposure and health-related risk estimation (Coleman, 1993; Morton \& Duck, 2001), perceived disease severity (Young, Norman, \& Humphreys, 2008), fear of cancer (Nelissen et al., 2015), and fear of terrorism (Nellis \& Savage, 2012; Silver et al., 2013). Shrum (2008) offered a cognitive explanation for such effects when he asserted that frequency of activation is sufficient to enhance the accessibility of constructs in memory. On this view, concepts become stronger and more easily activated as a function of frequency of activation:

H3: Fear is positively associated with frequency of exposure to threatrelated information via media channels.

Although there are many ways to define interpersonal communication, it is commonly conceived to be interaction between two individuals that takes place in real time (cf. Solomon \& Theiss, 2013). Compared to media research on risk and fear, findings regarding the effects of interpersonal communication are fewer in number and less consistent. For instance, Coleman (1993) found discussion effects for certain social risks but not for personal risks, whereas Trumbo (1996) reported that risk perceptions were driven by frequency of interpersonal discussion only among individuals who are predisposed toward amplification of risk. Work that assessed the perceived risks and benefits of a biological research facility showed frequency effects on benefits, but not risks (Binder, Scheufele, Brossard, \& Gunther, 2011). Thus, while the existing literature is hardly univocal, there is evidence of frequency effects for interpersonal discussion. The precise mechanism by which these effects occur may be debated, but the simplest explanation is that message repetition about a risky topic is sufficient to evoke fear regardless of channel. As with mediated messages, frequency of concept activation increases construct accessibility. Consequently, we make the following hypothesis: 
H4: Fear is positively associated with frequency of exposure to threatrelated information via interpersonal channels.

\section{Complexities in the Prediction of Fear?}

Prior research has indicated that interpersonal communication may interact with media exposure to alter individuals' knowledge, attitudes, or behaviors, either by amplifying the impact of media or by dampening it (e.g., Hardy \& Scheufele, 2005; Scheufele, 2000, 2001, 2002; Southwell \& Yzer, 2007, 2009). For example, Southwell (2005) found that the positive relationship between adolescents' exposure to an antidrug advertisement and their memory of it was moderated by interpersonal communications about the ad. Those who talked more about the ad remembered the ad content better. Similarly, interpersonal communication with family and friends has been shown to interact with Internet and television use to affect healthy lifestyle behaviors (Lee, 2009). Although previous research has seldom tested for this interaction on emotional response, it is plausible given that interpersonal conversations can amplify perceived risk. Thus we ask the following:

RQ1: Does interpersonal communication moderate the relationship between media exposure and fear of Ebola?

Although proximity to the outbreak of an infectious disease might be expected to create more intense fear responses, that may not be the only effect of location. Indeed, it seems likely that media tasked with reporting on local news might give greater coverage to the event than would national news. And residents of the city where the outbreak has occurred could be more inclined to discuss the matter with friends, family, and coworkers than would individuals at far remove. These higher levels of communication might differ in content or emphasis, making the threat appear more immediate or severe. These possibilities raise the following question:

RQ2: Is fear partially determined by an interaction between proximity and message exposure (media, interpersonal, or both)? 


\section{Method}

\section{Sample and Participants}

Participants were members of Qualtrics's opt-in, online survey panel. They received an invitation to participate via e-mail; provided data between October 21 and 29, 2014 (cf. Figure 1); then subsequently received compensation. As is generally the case with opt-in panels, response rate cannot be assessed because the number of invitations exceeds the a priori designated sample size. Once the target sample size is reached, the survey closes, and it is not known how many more participants would have accepted had it remained open.

Screening questions ensured that approximately half of the sample resided in the Dallas metropolitan area, whereas the remainder was balanced across census regions in the continental United States (but not including Texas). With the elimination of the 16 persons who spent more than 2 hours or fewer than 2 min completing the survey, the final sample $(N=849)$ was $46 \%$ male and $54 \%$ female, ranging in age from 18 to 64 years $(M=40.59, S D=14.01)$. As to ethnic identification, $74 \%$ of participants identified as White, $14 \%$ as Black or African American, 9\% as Hispanic, $5 \%$ as Asian or Pacific Islander, 3\% as Native American

TABLE 1 Comparison of Dallasites and Non-Dallasites

\begin{tabular}{lcccc}
\hline & Dallasites & Non-Dallasites & tor $x^{2}$ & $p$-Value \\
\hline Age (mean in years) & & 39 & 1.27 & 0.20 \\
Sample statistics & 41 & 37 & & \\
Population census data & 32 & & & \\
Gender (male; \%) & 55 & 50 & & \\
Sample statistics & 50 & & & \\
Population census data & & 78 & 5.33 & 0.001 \\
Ethnicity (White; \%) & 71 & 77 & & \\
Sample statistics & 51 & & & \\
Population census data & & & & \\
\hline
\end{tabular}

Note. Census data in the Non-Dallasites column are based on the entire United States, including Dallas. Census data on age for both Dallasites and non-Dallasites are median values in 2014. 
or American Indian, and $2 \%$ as "other," without specifying their ethnicity. Six percent of the participants identified with multiple ethnicities. There were 417 respondents from the Dallas metropolitan area and 432 from outside of Texas. Table 1 presents demographic comparisons of the two groups with one another and with census data. The study was approved by the Institutional Review Board at Pennsylvania State University.

\section{Statistical Power}

Assuming $\alpha=.05$, two-tailed, and $N=849$, power to detect a bivariate effect equal to $r$ of .10 was .83. Thus the study possessed adequate power to detect small effects.

\section{Measurement}

Demographics. Participants provided information on their gender $($ male $=1$; female $=0)$, ethnicity $($ White $=1$; non-White $=0)$, and age in years.

Proximity. A screening question asked respondents whether or not they lived in Dallas. Responses were verified against longitude and latitude data provided by Qualtrics. Location was a binary variable, where Dallas $=1$ and not Dallas $=-1$.

Message exposure via media and interpersonal channels. Level of exposure was estimated by asking respondents to estimate how often they have encountered information, in the past couple of months, about Ebola in newspapers or magazines; on television or radio; on the Internet; in conversation with friends or family; and in conversation with acquaintances, coworkers, or strangers. Judgments were made on a 5-point scale ranging from 1 (never) to 5 (more than 10 times). An index of interpersonal communication of Ebola information was created by averaging the two interpersonal channel items given that they were moderately correlated $(r=.66, \alpha=.80)$ and their relationships with other variables were parallel.

Fear. Using a response scale ranging from o (none of this emotion) to 4 (a great deal of this emotion), respondents were asked to mark the numerical values that best indicated how the current news about Ebola made them feel. Two items were drawn from a larger set of items whose 
TABLE 2 Descriptive Statistics

\begin{tabular}{lcccccc}
\hline & $M(S D)$ & 1 & 2 & 3 & 4 & 5 \\
\hline 1. Newspapers/mags & $2.86^{\mathrm{a}}(1.51)$ & - & & & & \\
2. TV/radio & $3.99^{\mathrm{a}}(1.27)$ & $0.36^{*}$ & - & & & \\
3. Internet & $3.68^{\mathrm{a}}(1.37)$ & $0.40^{*}$ & $0.34^{*}$ & - & & \\
$\begin{array}{l}\text { 4. Interpersonal } \\
\quad \text { communication }\end{array}$ & $3.12^{\mathrm{a}}(1.23)$ & $0.44^{*}$ & $0.44^{*}$ & $0.50^{*}$ & 0.80 & \\
5. Fear & & & & & & \\
\hline
\end{tabular}

Note. $N=849$. Values in the diagonal are Cronbach's alpha.

a Possible range $=1-5$. ${ }^{\text {} P o s s i b l e ~ r a n g e ~}=0-4$.

${ }^{*} p<.001$.

validity had been established in previous research (Dillard \& Shen, 2006). Given strong correlations with the latent variable fear (in those studies), it was determined that two items were sufficient to create a reliable index. Thus, to minimize respondent fatigue, we utilized only afraid and scared $(\alpha=.91)$.

\section{Results}

\section{Descriptive Results}

As shown in Table 2, on a o-4 scale, the mean value for fear was 1.62. However, the sample showed responses across the full range of the scale. For the five Ebola-related message exposure variables, the means ranged from 2.86 to 3.99 on a $1-5$ scale, which suggested medium to high levels of exposure to Ebola-related information.

\section{Model Fitting}

Two regression analyses were conducted with fear as the dependent variable. In both cases, the person variables were entered first as a block, followed by the mean-centered measures of mediated and interpersonal message exposure variables in the second block. In one analysis, the third block contained interaction terms for media and interpersonal exposure variables. In the other analysis, the third block contained product terms for location $(+1 /-1)$, with each of the mean-centered exposure indices. The results are given in Table 3 . 
TABLE 3 Regression Analyses Predicting Fear

\begin{tabular}{|c|c|c|c|c|c|c|}
\hline Block & Predictor & B & $95 \% \mathrm{Cl}$ & $\beta$ & $R$ & $R^{2} \Delta$ \\
\hline \multirow[t]{4}{*}{1} & Gender (male) & -.31 & $\begin{array}{l}-.48 \\
-.13\end{array}$ & $-.12^{* *}$ & .17 & $.03^{* * *}$ \\
\hline & Age & -.01 & $\begin{array}{l}-.01 \\
-.000\end{array}$ & $-.07^{*}$ & & \\
\hline & Ethnicity (White) & -.19 & $\begin{array}{l}-.39 \\
.004\end{array}$ & $-.07^{+}$ & & \\
\hline & Proximity (Dallas) & -.05 & $-.14, .04$ & -.04 & & \\
\hline \multirow[t]{4}{*}{2} & Newspapers/mags & .10 & $.03, .16$ & $.11^{* *}$ & .26 & $.04^{* * *}$ \\
\hline & TV/radio & -.04 & $-.12, .04$ & -.04 & & \\
\hline & Internet & -.11 & $\begin{array}{l}-.18 \\
-.03\end{array}$ & $-.12^{* *}$ & & \\
\hline & Interpersonal & .19 & $.10, .28$ & $.18^{* * *}$ & & \\
\hline \multirow[t]{3}{*}{$3 a$} & $\begin{array}{l}\text { Interpersonal } \times \\
\text { Newspapers/Mags }\end{array}$ & .04 & $-.01, .09$ & -.06 & .27 & .004 \\
\hline & Interpersonal $\times$ TV/Radio & .01 & $-.06, .07$ & .01 & & \\
\hline & Interpersonal $\times$ Internet & -.04 & $-.11, .02$ & -.06 & & \\
\hline \multirow[t]{4}{*}{$3 b$} & $\begin{array}{l}\text { Proximity } \times \text { Newspapers/ } \\
\text { Mags }\end{array}$ & -.01 & $-.08, .06$ & -.01 & .28 & .002 \\
\hline & Proximity $\times$ TV/Radio & .01 & $-.07, .09$ & .01 & & \\
\hline & Proximity $\times$ Internet & .03 & $-.05, .10$ & .03 & & \\
\hline & Proximity $\times$ Interpersonal & -.01 & $-.11, .08$ & -.01 & & \\
\hline
\end{tabular}

Note. $N=849$. Regression coefficients in Block 1 were estimated using only predictors in that block. The Block 2 estimates are based on the full set of predictors in Blocks 1 and 2. Similarly, Block 3 estimates are based on all prior blocks.

${ }^{+} p=.055 .{ }^{*} p<.05 .{ }^{* *} p<.01$. ${ }^{* * *} p<.001$.

\section{Hypothesis Tests}

H1A, which predicted a negative association with gender, was supported. The standardized coefficient, $\beta=-.12, p=.001$, indicated that men reported lower levels of fear than women. н1в anticipated a negative relationship between age and fear. With $\beta=-.07, p=.039$, the hypothesis was supported. Older respondents experienced fear less intensely 
than their younger counterparts. H1C predicted a negative coefficient for ethnicity, which was borderline significant, $\beta=-.07, p=.055$.

$\mathrm{H} 2$ specified a positive association between proximity to the outbreak and fear. Because the observed difference between Dallas residents and nonresidents was not significant, $\beta=-.04, p=.277$, this hypothesis was not supported.

$\mathrm{H} 3$ predicted positive associations between fear and indices of media exposure. The regression analysis estimated these relationships as follows: for newspapers/magazines, $\beta=.12, p=.003$; for TV/radio, $\beta=$ $-.04, p=.341$; for Internet, $\beta=-.12, p=.005$. Support for $\mathrm{H} 3$ was mixed.

Similarly, $\mathrm{H} 4$ anticipated positive effects for interpersonal exposure on fear. Indeed, exposure to Ebola information via interpersonal channels significantly predicted fear, $\beta=.18, p<.001$. Thus $\mathrm{H} 4$ was supported.

RQ1 focused on the interaction effects between interpersonal and media exposure to Ebola messages (see Block za in Table 3). We used the mean-centered interpersonal and media exposure variables to create the interaction terms (product terms). $R^{2}$ change for the block was $.004, p=.351$. None of the terms was significant. Thus there was no interaction effect of message exposure on fear via different channels.

RQ2 examined the potential for proximity and message exposure to interact in their effect on fear. Block $3 \mathrm{~b}$ of Table 3 assessed the data for these interactions. $R^{2}$ change for the block was .002, $p=.839$, and none of the individual terms was significant. Thus message exposure effects were not conditioned on location.

\section{Discussion}

\section{The Intensity of Fear}

A majority of our sample (80\%) reported experiencing some degree of fear (i.e., $>0$ on a $0-4$ scale). Yet, the mean value of 1.62 seemed rather modest and not in keeping with news characterizations of the public mood as an "epidemic of fear and anxiety" (Harlan, 2014). To put these values in perspective, it may be useful to consider two points of reference. On one hand, levels of fear and perceived threat in the data were comparable to the SARS outbreak in 2003 and the $\mathrm{H}_{1} \mathrm{~N}_{1}$ pandemic in 2009. In both cases, more than half of the Americans surveyed 
indicated that they were not that worried about the threat (Moore, 2003; Pew Research Center, 2003, 2009; Saad, 2009). From this, it seemed sensible to conclude that the Ebola crisis was nontrivial but that media interpretations of it were overblown.

On the other hand, Americans were far more concerned than they should have been. The level of fear reported by our sample might be viewed as a vast overreaction to the true risk posed by Ebola. Indeed, one Internet meme held that Americans were more likely to marry a Kardashian $(n=3)$ than to die from Ebola $(n=1)$. According to health experts (e.g., Friedman \& Schapiro, 2014), the Kardashian comparison was reasonably accurate. Thus the series of events was psychologically significant for many members of the public, despite the fact that high levels of fear were not objectively justified.

\section{Personal Predictors of Fear: Demographics}

Demographic variables were included in this study to determine whether fear varied as a function of group membership. On this point, the data provided some reasonably clear answers. Persons who were female, younger, and non-White all showed heightened levels of fear of Ebola. These results are consistent with prior research showing that membership in these categories is associated with higher fear levels for other sorts of adverse events (e.g., Campbell et al., 2016; Charles, Reynolds, \& Gatz, 2001; Chu et al., 2006). To the extent that Ebola is representative of other infectious diseases, this provides a rationale for demographically targeted communication efforts designed to reduce public fear during times of crisis.

The results also suggest the existence of a heretofore unidentified form of health disparity, one based on emotional response. Members of these demographically defined groups, and especially those who belong to multiple categories, are at relatively greater risk for the subjective experience of fear as well as downstream effects, such as diminished biological and psychological health (Segerstrom et al., 1998; Silver et al., 2013).

There is, however, one important qualification to these conclusions. Because our sample was $74 \%$ White, we were unable to provide meaningful tests of differences among minority groups (which have 
been observed in some previous work, e.g., Chu et al., 2006). More research is needed to better understand the prevalence and basis of group differences.

\section{Personal Predictors of Fear: Proximity}

A proximity effect was anticipated, such that Dallasites would be more frightened than persons living outside of Texas. Because the data did not show the expected effect, we considered alternative explanations. One was that media content varied in ways that dampened fear in Dallas or exacerbated it outside of Texas. With the aim of exploring this possibility, we searched for, but did not find, systematic comparisons of communication content in Dallas versus not Dallas. However, an analysis of one Canadian and one Nigerian newspaper offered an ana$\log$ (Humphries, Radice, \& Lauzier, 2017). Two consistent themes in the Canadian paper, which was geographically distant from the threat of Ebola, were an emphasis on global responsibility for combating the disease and the need for the Canadian government to stop Ebola before it spread into Western nations. The Nigerian paper, in contrast, focused on the risks of Ebola and the actions undertaken locally to safeguard the population. In addition, the Nigerian outlet more frequently critiqued Western coverage of Ebola as sensationalistic and actively resisted perceived stigmatization of Nigerians. In other words, the Canadian "outsider" paper framed Ebola more reactively, whereas the Nigerian "insider" publication gave greater emphasis to action and ingroup solidarity. Although our reasoning is obviously speculative, if the same communication dynamics were at work in our U.S. sample, they may have been responsible for the absence of a proximity effect in the data.

Another possibility is that precisely the opposite occurred; that is, rather than different locales producing different content, it is conceivable that news coverage did not vary. On this view, the Ebola crisis was treated by all news outlets as a national issue, and the public, regardless of location, perceived it as such. This account aligns well with Holman et al.s (2014) data. Their work on the Boston Marathon bombing found no effect for physical proximity on acute stress symptoms but a positive, linear effect for media exposure. Together, the two results suggest 
a media environment that defines the crisis broadly enough to override the influence of geography.

Both possibilities are compatible with one broader point. Although we thought it plausible that individuals closer to the threat would see themselves as more susceptible to it (and therefore experience greater fear), physical distance is not synonymous with psychological distance (Trope \& Liberman, 2010). Going forward, researchers may wish to examine factors that moderate the correspondence between these two related but independent forms of distance.

\section{Media and Interpersonal Predictors of Fear}

The social amplification of risk model asserts that amplification stations function to modulate perceptions of risk, by either magnification or minimization. Our results are intriguing in that they demonstrate effects of both sorts as well as a null effect for TV/radio. As for amplification, frequency of exposure via newspapers/magazines showed the anticipated positive association with fear. This result echoes findings from many previous studies that reported an influence of media exposure on risk (e.g., Coleman, 1993; Young et al., 2008) but joins a relatively small number of investigations that found a parallel effect on fear (Nelissen et al., 2015; Silver et al., 2013). Interpersonal communication also showed positive relationships such that more frequent exposure to Ebola-related communication led to higher levels of fear of Ebola.

The observed effect of exposure is compatible with theories of memory that hold that semantically related words or concepts co-occur with the target more easily and frequently (Anderson, 1983; Dosher \& Rosedale, 1989). Repeated exposure to the same stimuli has been found to facilitate memory of the stimuli-a phenomenon known as repetition priming (Logan, 1990). According to these theories, simple mention of Ebola should be sufficient to activate the cognitive appraisals that are responsible for fear.

That simple account is challenged, however, by the findings for TV/ radio, which showed no detectable association with fear, and for Internet exposure, which was negatively correlated with fear. At the broadest level, these results are important in that they empirically illustrate the potential for different amplification stations to produce countervailing 
(or no) effects for a specific threat. Although it is unclear whether this pattern of results is unique to Ebola or generalizable to other infectious diseases, it underscores the need to consider the interplay of influences within and across the categories of interpersonal and mediated communication.

At a more specific level, the study showed that newspapers/magazines were positively associated with fear, whereas Internet usage produced a negative association. While a definitive account of the findings is not possible, personal agency and message content may both play a role. In contrast to the sensationalism of corporate media, active seekers of information about Ebola may have sought and found-via the Internet-credible sources of health information, most which were saying that the risk of Ebola in the United States was vanishingly small (Friedman \& Schapiro, 2014).

\section{Complex Influences on Fear?}

No interpersonal/media interaction effect was observed in this study. In other words, there was no indication that conversations about Ebola magnified or minimized the impact of media exposure on fear. Naturally, this raises the question of why interaction effects appear in some studies (e.g., Lee, 2009) and not others (e.g., the current project). Simply posing this question highlights a lacuna in the research literature. Although the possibility of interpersonal/media interactions has been raised, there is currently no theory designed to explain when or why such effects should be expected. Because research has suggested multiple factors that might govern the effect-message function, format, timing, topic, and network density (Southwell \& Yzer, 2009)-it is clear that constructing such a theory will be a nontrivial, but much needed, undertaking.

In a similar vein, we considered the possibility that location would interact with message exposure. None of the four tests was significant. Although Ebola-related message exposure was generally higher in Dallas versus outside of Texas, there was no indication that the exposure-fear association varied in strength as a function of location. This null effect could be due to Ebola being seen as a national rather than local phenomenon at the time of our investigation. Indeed, many 
newsworthy events took place beyond the Texas border. Schools were closed in Ohio as well as in Texas (Szabo, 2014), and both New York and New Jersey imposed a quarantine on travelers with possible Ebola contacts (Thompson, 2014). Of course, the possibility of sampling error cannot be ruled out.

\section{Strengths and Limitations}

This investigation has several noteworthy strengths, including a relatively large sample gathered at a critical moment in the unfolding of a real-world event. In addition, the results are reasonably clear, offering support for some expectations and an unequivocal lack of support for others.

Of course, the study also possesses noteworthy limitations. It is hard to generalize the findings to other infectious diseases given that the data are limited to one disease in one Western country at one point in history. Second, strictly speaking, cross-sectional data preclude causal inference. However, the nature of the variables under study tempers this principle. For example, it seems implausible that fear of Ebola exerted a causal influence on individuals' reporting of their gender, age, ethnicity, or location. However cross-sectional data do not allow us to rule out the possibility that fear influenced reporting of interpersonal and media exposure measures. But, at least in the case of media exposure, there is evidence that self-reports are reasonably valid indicators of more objective measures of the same variable (Southwell, Barmada, Hornik, \& Maklan, 2002). Additional research using longitudinal or experimental designs is needed to sort out questions of causal flow.

Third, the nonprobability sample was not representative of the nation generally nor of Dallas specifically. Accordingly, point estimates in our data must be viewed with caution. Another substantial limitation to this investigation was the absence of measures of communication content. Having such information would have aided our interpretation of several findings, especially those concerned with interpersonal and media exposure. Future research would benefit from the inclusion of even gross indices of content. Work that links content analysis of media with individual-level data on interpersonal communication and fear would be especially valuable. 
Finally, our indices of communication were relatively crude. Interpersonal communication was undefined for participants, which may have introduced error into the data to the extent that interpretations of the phrase varied across the sample. And the media measures were not sufficiently granular to capture exposure via social media channels like Instagram and Twitter (Sellnow-Richmond et al., 2018). Both weaknesses should be corrected in future research.

\section{Conclusions}

Using data gathered near the peak of a perceived disease crisis, this study yielded several important findings: (a) Widespread fear of infectious disease is possible, even when the objective level of risk is extremely low; (b) being young, female, and non-White are risk factors for high levels of fear; and (c) media and interpersonal amplification stations are likely complicit in magnifying fear but (d) can also serve to counteract it. Collectively, these observations contribute to our general understanding of public reactions to infectious disease and point the way forward toward interventions designed to mitigate negative emotional reactions.

James Price Dillard, $\mathrm{PhD}$, is distinguished professor of communication arts and sciences at the Pennsylvania State University. His research focuses on how messages induce emotions and when those emotions change attitudes and actions.

Chun Yang, PhD, is assistant professor of public relations in the Manship School of Mass Communications at Louisiana State University. His research interests include strategic communication and the emotional and cognitive effects of media and media strategies.

\section{ORCID}

James Price Dillard (D) https://orcid.org/oooo-0oo1-8109-1562 


\section{Notes}

1. Of course, not everyone agrees. For example, Gray and McNaughton (2000) contended that fear is an acute response to immediate danger that can be remedied, whereas anxiety is a response to a future threat that cannot be avoided. Lazarus (1991) differentiated them in terms of physical versus existential threat. However, even inventories designed to measure fear and anxiety as separate constructs find an average correlation of .46 (Sylvers, Lilienfeld, \& LaPrairie, 2011). Though it may be useful to distinguish fear and anxiety for certain purposes, we see their difference mostly as a matter of degree.

2. The terminology is regrettable in that stations can amplify or attenuate perceptions of risk. Phrasing such as modulation stations would more accurately convey what is meant. But, because the phrase amplification stations is now embedded into the research literature, we bow to previous usage.

\section{References}

Alcabes, P. (2009). Dread: How fear and fantasy have fueled epidemics from the Black Death to Avian flu. New York, NY: Public Affairs Books.

Anderson, J. R. (1983). The architecture of cognition. Cambridge, MA: Harvard University Press.

Barrett, R., \& Brown, P. J. (2008). Stigma in the time of influenza: Social and institutional responses to pandemic emergencies. Journal of Infectious Diseases, 197(S1), 34-37. https://doi.org/10.1086/524986

Binder, A., Scheufele, D., Brossard, D., \& Gunther, A. (2011). Interpersonal amplification of risk? Citizen discussions and their impact on perceptions of risks and benefits of a biological research facility. Risk Analysis, 31, 324-334. https://doi.org/10.1111/j.1539-6924.2010.01516.x

Bruinius, H. (2014, November 1). Ebola doctor speaks out on "media frenzy" and the quarantine he faces. Christian Science Monitor. Retrieved from http://www.csmonitor.com/USA/2014/1101/Ebola-doctor-speaks-out-on -media-frenzy-and-the-quarantine-he-faces-video

Campbell, A., Coombes, C., David, R., Opre, A., Grayson, L., \& Muncer, S. (2016). Sex differences are not attenuated by a sex-invariant measure of fear: The situated fear questionnaire. Personality and Individual Differences, 97, 210-219. https://doi.org/10.1016/j.paid.2016.03.049 
Carstensen, L. L. (2006). The influence of a sense of time on human development. Science, 312, 1913-1915. https://doi.org/10.1126/science.1127488

Centers for Disease Control and Prevention. (2015, May). Ebola (Ebola virus disease). Retrieved from http://www.cdc.gov/vhf/ebola/

Charles, S. T. (2010). Strength and vulnerability integration: A model of emotional well-being across adulthood. Psychological Bulletin, 136, 1068-1091. https://doi.org/10.1037/aoo21232

Charles, S. T., Reynolds, C. A., \& Gatz, M. (2001). Age-related differences and change in positive and negative affect over 23 years. Journal of Personality and Social Psychology, 80, 136-151. https://doi.org/10.1037/0022-3514.80.1.136

Chu, T. Q., Seery, M. D., Ence, W. A., Holman, A., \& Silver, R. C. (2006). Ethnicity and gender in the face of a terrorist attack: A national longitudinal study of immediate responses and outcomes two years after September 11. Basic and Applied Social Psychology, 28, 291-301. https://doi.org/10.1207 /s15324834basp2804_2

Coleman, C. (1993). The influence of mass media and interpersonal communication on societal and personal risk judgments. Communication Research, 2o, 611-628. https://doi.org/10.1177/009365093020004006

Dillard, J. P., \& Shen, L. (2006). Self-reports of discrete emotions. In R. A. Reynolds, R. Woods, \& J. D. Baker (Eds.), Handbook of research on electronic surveys and measurements (pp. 330-333). Hershey, PA: IGR.

Dosher, B. A., \& Rosedale, G. (1989). Integrated retrieval cues as a mechanism for priming in retrieval from memory. Journal of Experimental Psychology: General, 118, 191-211. https://doi.org/10.1037/oo96-3445.118.2.191

Finucane, M., Slovic, P., Mertz, C. K., Flynn, J., \& Satterfield, T. (2000). Gender, race and perceived risk: The "White male" effect. Health, Risk, and Society, 2, 159-172. https://doi.org/10.1080/713670162

Flynn, J., Slovic, P., \& Mertz, C. K. (1994). Gender, race, and perception of environmental health risks. Risk Analysis, 14, 1101-1108. https://doi .org/10.1111/j.1539-6924.1994.tbooo82.x

Friedman, D., \& Schapiro, R. (2014, October 16). CDC head assures Ebola not serious risk to U.S. New York Daily News. Retrieved from http://www .nydailynews.com/life-style/health/texas-hospital-deeply-ebola-mistakes -article-1.1976195

Frijda, N. H. (1986). The emotions. London, England: Cambridge University Press.

Gilsinan, K. (2014, October 30). "An epidemic of fear": Ebola in the United 
States. The Atlantic. Retrieved from http://www.theatlantic.com/interna tional/archive/2014/10/an-epidemic-of-fear-ebola-in-the-united-states /382158/

Gray, J. A., \& McNaughton, N. (2000). The neuropsychology of anxiety (2nd ed.). New York, NY: Oxford University Press.

Hardy, B. W., \& Scheufele, D. A. (2005). Examining differential gains from Internet use: Comparing the moderating role of talk and online interactions. Journal of Communication, 55, 71-84. https://doi.org/10.1111/j .1460-2466.2005.tbo2659.x

Harlan, C. (2014, October 15). An epidemic of fear and anxiety hits Americans amid Ebola outbreak. Washington Post. Retrieved from http://www .washingtonpost.com/business/economy/an-epidemic-of-fear-and-anxiety -hits-americans-amid-ebola-outbreak/2014/10/15/o76ofb96-54a8-11e4 -ba4b-f6333e2co453_story.html

Hartley, D. J., Davila, M. A., Marquart, J. W., \& Mullings, J. L. (2013). Fear is a disease: The impact of fear and exposure to infectious disease on correctional officer job stress and job satisfaction. American Journal of Criminal Justice, 38, 323-340. https://doi.org/10.1007/s12103-012-9175-1

Holman, E. A., Garfin, D. R., \& Silver, R. C. (2014). Media's role in broadcasting acute stress following the Boston Marathon bombings. Proceedings of the National Academy of Sciences of the United States of America, 111, 93-98. https://doi.org/10.1073/pnas.1316265110

Humphries, B., Radice, M., \& Lauzier, S. (2017). Comparing "insider" and "outsider" news coverage of the 2014 Ebola outbreak. Canadian Journal of Public Health, 108, E381-E387. https://doi.org/10.17269/CJPH.108.5904

Kasperson, J. X., Kasperson, R., Pidgeon, N. F., \& Slovic, P. (2003). The social amplification of risk: Assessing fifteen years of research and theory. In N. F. Pidgeon, R. K. Kasperson, \& P. Slovic (Eds.), The social amplification of risk (pp. 13-46). Cambridge, England: Cambridge University Press.

Kim, H. K., \& Niederdeppe, J. (2013). The role of emotional response during an $\mathrm{H}_{1} \mathrm{~N}_{1}$ influenza pandemic on a college campus. Journal of Public Relations Research, 25, 30-50. https://doi.org/10.1080/1062726X.2013.739100

Lazarus, R. (1991). Emotion and adaptation. New York, NY: Oxford University Press.

Lee, C.-J. (2009). The interplay between media use and interpersonal communication in the context of healthy lifestyle behaviors: Reinforcing or 
substituting? Mass Communication and Society, 13, 48-66. https://doi .org/10.1080/15205430802694869

Lempel, H., Epstein, J. M., \& Hammond, R. A. (2009). Economic cost and health care workforce effects of school closures in the U.S. PLoS Currents, 1, RRN1051. https://doi.org/10.1371/currents.RRN1051

Liu, B. F., Fraustino, J. D., \& Jin, Y. (2017). Back to basics: Examining key demographics in new media and crisis communication. In S. Duhé (Ed.), New media and public relations (pp. 312-327). New York, NY: Peter Lang. Logan, G. D. (1990). Repetition priming and automaticity: Common underlying mechanisms? Cognitive Psychology, 22, 1-35. https://doi.org/10.1016/oo10 $-0285(90) 90002-\mathrm{L}$

Moore, D. (2003, April 25). Worry about SARS increases: More than 4 in 10 Americans worried, up by a third in a week. Retrieved from http://www .gallup.com/poll/826o/Worry-About-SARS-Increases.aspx

Morgan, M., \& Shanahan, J. (1997). Two decades of cultivation research: An appraisal and meta-analysis. In B. R. Burleson (Ed.), Communication Yearbook 20 (pp. 1-45). Thousand Oaks, CA: Sage.

Morton, T., \& Duck, J. (2001). Communication and health beliefs. Communication Research, 28, 602-626. https://doi.org/10.1177/009365001028005002

Nelissen, S., Beullens, K., Lemal, M., \& Van den Bulck, J. (2015). Predictors of cancer fear: The association between mass media and fear of cancer among cancer diagnosed and nondiagnosed individuals. Journal of Cancer Education, 30, 68-74. https://doi.org/10.1007/s13187-014-0705-Z

Nellis, A. M., \& Savage, J. (2012). Does watching the news affect fear of terrorism? The importance of media exposure on terrorism fear. Crime \& Delinquency, 58, 748-768. https://doi.org/10.1177/oo11128712452961

Ortony, A., Clore, G. L., \& Collins, A. (1988). The cognitive structure of emotions. Cambridge, England: Cambridge University Press.

Pew Research Center. (2003, June 3). Views of a changing world 2003: War with Iraq further divides global publics. Retrieved from http://www.pewglobal .org/2003/o6/03/views-of-a-changing-world-2003/

Pew Research Center. (2009, September 3). Public aware of key swine flu facts: Health care debate still top story. Retrieved from http://www.people-press .org/2009/09/03/public-aware-of-key-swine-flu-facts/

Rimé, B. (2007). Interpersonal emotion regulation. In J. J. Gross (Ed.), Handbook of emotion regulation (pp. 466-485). New York, NY: Guilford Press. 
Ruiz, C., \& Hernandez, B. (2014). Emotions and coping strategies during an episode of volcanic activity and their relations to place attachment. Journal of Environmental Psychology, 38, 279-287. https://doi.org/10.1016/j .jenvp.2014.03.008

Saad, L. (2009, June 15). Despite "pandemic," swine flu worry dwindles: Few in any region are worried; gender gap gone. Retrieved from http://www.gallup .com/poll/120863/Despite-Pandemic-Swine-Flu-Worry-Dwindles.aspx

Scheufele, D. A. (200o). Talk or conversation? Dimensions of interpersonal discussion and their implications for participatory democracy. Journalism \& Mass Communication Quarterly, 77, 727-743. https://doi.org/10.1177 /107769900007700402

Scheufele, D. A. (2001). Democracy for some? How political talk both informs and polarizes the electorate. In R. P. Hart \& D. Shaw (Eds.), Communication and U.S. elections: New agendas (pp. 19-32). Lanham, MD: Rowman \& Littlefield.

Scheufele, D. A. (2002). Examining differential gains from mass media and their implications for participatory behavior. Communication Research, 29, 46-65. https://doi.org/10.1177/0093650202029001003

Schulz, J. M., Cooper, J. L., Baingana, F., Oquendo, M. A., Espinel, Z., Althouse, B. M., ... Rechkemmer, A. (2016). The role of fear-related behaviors in the 2013-2016 West African Ebola virus disease outbreak. Current Psychiatry Reports, 18, 104. https://doi.org/10.1007/s11920-016-0741-y

Segerstrom, S. C., Solomon, G. F., Kemeny, M. E., \& Fahey, J. L. (1998). Relationship of worry to immune sequelae of the Northridge earthquake. Journal of Behavioral Medicine, 21, 433-450. https://doi.org/10.1023/A:1018732309353

Sellnow-Richmond, D. D., George, A. M., \& Sellnow, D. D. (2018). An IDEA model analysis of instructional risk communication in the time of Ebola. Journal of International Crisis and Risk Communication Research, 1, 135-166. https://doi.org/10.30658/jicrcr.1.1.7

Shrum, L. J. (2008). Media consumption and perceptions of social reality: Effects and underlying processes. In J. Bryant \& D. Zillman (Eds.), Media effects: Advances in theory and research (pp. 69-95). Mahwah, NJ: Erlbaum. Silver, R. C., Holman, E. A., Andersen, J. P., Poulin, M., McIntosh, D. N., \& Gil-Rivas, V. (2013). Mental- and physical-health effects of acute exposure to media images of the September 11, 2001, attacks and Iraq War. Psychological Science, 24, 1623-1634. https://doi.org/10.1177/0956797612460406 Smith, R. D. (2006). Responding to global infectious disease outbreaks: Lessons 
from SARS on the role of risk perception, communication and management. Social Science \& Medicine, 63, 3113-3123. https://doi.org/10.1016/j .socscimed.2006.08.004

Solomon, D. H., \& Theiss, J. T. (2013). Interpersonal communication: Putting theory into practice. New York, NY: Routledge.

Southwell, B. G. (2005). Between messages and people: A multilevel model of memory for television content. Communication Research, 32, 112-140. https://doi.org/10.1177/0093650204271401

Southwell, B. G., Barmada, C. H., Hornik, R. C., \& Maklan, D. M. (2002). Can we measure encoded exposure? Validation from a national campaign. Journal of Health Communication, 7, 445-453. https://doi.org/10.1080 /10810730290001800

Southwell, B. G., \& Yzer, M. C. (2007). The roles of interpersonal communication in mass media campaigns. Annals of the International Communication Association, 31, 420-462. https://doi.org/10.1080/23808985.2007.11679072

Southwell, B. G., \& Yzer, M. C. (2009). When (and why) interpersonal talk matters for campaigns. Communication Theory, 19, 1-8. https://doi.org/10 $.1111 / \mathrm{j} .1468-2885.2008 .01329 . \mathrm{x}$

Stitka, L. J., Bauman, C. W., \& Mullen, E. (2004). Political tolerance and coming to psychological closure following the September 11, 2001, terrorist attacks: An integrative approach. Personality and Social Psychology Bulletin, 30, 743-756. https://doi.org/10.1177/014616720426398

Suls, J., \& Bunde, J. (2005). Anger, anxiety, and depression as risk factors for cardiovascular disease: The problems and implications of overlapping affective dispositions. Psychological Bulletin, 131, 260-300. https://doi .org/10.1037/0033-2909.131.2.260

Sun, L. H., Dennis, B., Bernstein, L., \& Achenbach, J. (2014, October 4). Out of control: How the world health organizations failed to stop the Ebola disaster. Washington Post. Retrieved from http://www.washingtonpost .com/sf/national/2014/10/04/how-ebola-sped-out-of-control/

Sylvers, P., Lilienfeld, J. L., \& LaPrairie, J. L. (2011). Differences between trait fear and trait anxiety: Implications for psychopathology. Clinical Psychology Review, 31, 122-137. http://doi.org/10.1016/j.cpr.2010.08.004

Szabo, L. (2014, October 14). Doctors: School closings in Texas, Ohio unnecessary. USA Today. Retrieved from https://www.usatoday.com/story/news /nation/2014/10/16/solon-ohio-ebola-school-closings/17343431/

Tamir, M. (2016). Why do people regulate their emotions? A taxonomy of 
motives in emotion regulation. Personality and Social Psychology Review, 20, 199-222. https://doi.org/10.1177/1088868315596325

Thompson, D. (2014, October 25). New York, New Jersey to quarantine all travelers with Ebola contacts. MedicineNet. Retrieved from https://www .medicinenet.com/script/main/art.asp?articlekey $=184895$

Trope, Y., \& Liberman, N. (2010). Construal-level theory of psychological distance. Psychological Review, 117, 440-463. http://doi.org/10.1037/aoo18963

Trumbo, C. W. (1996). Examining psychometrics and polarization in a singlerisk case study. Risk Analysis, 16, 429-437. https://doi.org/10.1111/j.1539 -6924.1996.tbo1477.x

U.S. Senate Committee on Health, Education, Labor, and Pensions. (2014, September 16). Alexander: We must take the deadly, dangerous threat of Ebola as seriously as ISIL. Retrieved from http://www.help.senate.gov /newsroom/press/release/?id=f75a8f7c-403b-

Van Bortel, T., Basnayake, A., Wurie, F., Jambai, M., Koroma, A. S., Muana, A. T.,... Nellums, L. B. (2016). Psychosocial effects of an Ebola outbreak at individual, community, and international levels. Bulletin of the World Health Organization, 94, 210-214. https://doi.org/10.2471/BLT.15.158543

White, J. L., \& Parham, T. A. (1990). The psychology of Blacks: An African American perspective (2nd ed.). Englewood Cliffs, NJ: Prentice Hall.

World Health Organization. (2015, April). Ebola virus disease. Retrieved from http://www.who.int/mediacentre/factsheets/fs103/en

Yamanis, T., Nolan, E., \& Shepler, S. (2016). Fears and misperceptions of the Ebola response system during the 2014-2015 outbreak in Sierra Leone. PLoS Neglected Tropical Diseases, 10(10), eoo05077. https://doi.org/10.1371/jour nal.pntd.0005077

Young, M. E., Norman, G. R., \& Humphreys, K. R. (2008). Medicine in the popular press: The influence of the media on perceptions of disease. PLoS One, 3, e3552. https://doi.org/10.1371/journal.pone.0003552

Zhuang, J., Peng, T.-Q., \& Tang, J. (2018). Scared, angry, or sad about Ebola? Emotional responses to 2014 Ebola outbreak. Unpublished manuscript. 